\title{
Views of Mothers about National Newborn Screening Tests Performed in Turkey
}

\author{
Şenay Topuz ${ }^{1,}$, Asena Taşgit ${ }^{2}$, Elif Çilesiz ${ }^{3}$, Rüveyda Gökce, Derya Aycan Ülger ${ }^{4}$ and Ş. Suna Oğuz ${ }^{5}$ \\ ${ }^{1}$ Assistant Professor, Department of Midwifery, Faculty of Nursing, Ankara University Ankara, Turkey \\ 2 Nurse, University of Health Sciences Zekai Tahir Burak Women's Health Training and Research Hospital, Ankara, Turkey \\ ${ }^{3}$ Research Assistant, Department of Midwifery, Faculty of Health Sciences, Amasya University, Amasya, Turkey \\ ${ }^{4}$ Midwife, Turkey Republic Ministry of Health \\ ${ }^{5}$ Associate Professor, University of Health Sciences Zekai Tahir Burak Women’s Health Training and Research Hospital, Ankara, Turkey \\ * Corresponding author: Şenay Topuz, Department of Midwifery, Faculty of Nursing, Ankara University, Ankara, Turkey. Tel: \\ +905053785304; Email: senaytopuz@gmail.com
}

Received 2021 February 15; Revised 2021 March 25; Accepted 2021 April 18

\section{Abstract}

Background: Newborn screening tests for detecting numerous congenital diseases that may cause disability or death were performed first in 2006 in Turkey. Newborn screenings for Phenylketonuria and congenital hypothyroidism have increased in recent years due to the emergence of new diseases. It is essential for healthcare personnel and families to carry out these screening programs in a timely, accurate, and efficient manner. Informing families, particularly mothers, about these screening tests will help more newborn babies benefit from these tests.

Objectives: This study aimed to explore mothers' views about newborn screening programs in Turkey.

Methods: This descriptive and cross-sectional study included 112 volunteer mothers and was conducted at Zekai Tahir Burak Hospital, Ankara, Turkey, from December 2018 to January 2019.

Results: Although mothers in Turkey were to some extent informed about the screening tests, they did not have sufficient information regarding the objective of these tests. Moreover, the majority of mothers expressed a positive opinion about the tests and stated that they would have these tests done even if they had to pay for them.

Conclusion: Based on the obtained results, although mothers in turkey were not sufficiently knowledgeable about screening tests and their objectives, they expressed positive views about these tests. Therefore, it is recommended that families should be informed about newborn screening tests through mass media, educational environments (pregnancy schools), and screening test centers. Therefore, it is important to organize in-service training for midwives and nurses to raise their awareness in this regard.

Keywords: Mothers, Newborn, Screening test
\end{abstract}

\section{Background}

Newborn screening programs are important preventive health services under public health programs in both developed and developing countries around the world (1). National screening programs are conducted for treatable newborn diseases that are prevalent in the Turkey community. Newborn screening program includes tests that are conducted after birth and can detect numerous congenital diseases that may affect the whole life of the newborn and even cause death at an early age $(1,2)$. Newborn screening programs in turkey include the Turkish newborn screening program, Neonatal Screening Program (NSP), Newborn Hearing Screening Program (NHSP), and Screening for Developmental Dysplasia of the Hip (SDDH). Screening newborns for phenylketonuria and congenital hypothyroidism using heel lance procedure has been compulsory in Turkey since 2006 as part of the NSP. The scope of this program was expanded to include biotinidase deficiency in 2008 and cystic fibrosis in 2015. Congenital adrenal hyperplasia screenings were initiated in Konya, Adana, Kayseri, and Samsun Provinces, as pilot cities, in 2017. Moreover, NHSP and SDDH were initiated in 2004 and 2010, respectively $(3,4)$.

Consanguineous marriages increase the incidence and prevalence of congenital diseases. The rate of consanguineous marriages is high (23.2\%) in Turkey (5). This high rate of consanguineous marriages increases the importance of newborn screenings. Therefore, due to the high rate of consanguineous marriages in Turkey, it is vital to detect congenital diseases and start treatments after birth at the earliest time possible $(6,7)$.

The responsible health care personnel and newborns' families play a central role in conducting these screening programs in a timely, adequate, and efficient manner (8-10). Furthermore, knowledge and awareness of the families, especially mothers, about screening programs are essential factors in the successful implementation of screening programs. If mothers are not sufficiently knowledgeable about national screening programs and have negative opinions about these tests, they will refuse to have their infants tested in time to prevent their babies from getting hurt by invasive interventions (e.g. heel lance). The study conducted by Doğruel revealed that people did not bring their children to be screened for developmental dysplasia of the hip even though they were educated about developmental dysplasia of the 
hip (DDH) (11).

\section{Objectives}

This study aimed to explore mothers' views regarding newborn screening programs.

\section{Methods}

The study population in this descriptive and cross-sectional study included the mothers of newborns admitted in the newborn clinics of Zekai Tahir Burak Woman's Health Training and Research Hospital, affiliated with the University of Health Sciences, Ankara, Turkey, between December 2018 and January 2019. The study objectives were explained to 112 mothers who agreed to participate in this study and sampling was conducted among mothers who gave verbal consent for participation in the study. The data obtained from the study literature were presented as a 43 items questionnaire regarding the sociodemographic characteristics of the participants and their knowledge of newborn screening programs $(9,12-14)$. The necessary corrections were made on the sociodemographic characteristics forms and they took their final form after data collection was tried on five parents using the initial questionnaires. Research data were collected through face-to-face interviews with 112 mothers whose written and verbal consent were obtained previously. The time required for the completion of each questionnaire was approximately 10-15 minutes. Data were analyzed in SPSS software (version 24, 0) through percentage calculations and Fisher's chi-square test.

After questions were asked, mothers who took the survey were generally informed about the importance of neonatal screening programs.

\section{Results}

\subsection{Mother's sociodemographic characteristics}

Mothers' sociodemographic characteristics are presented in Table 1. Based on the data in Table 1, $42.9 \%, 30.4 \%$, and $74.3 \%$ of the mothers were in the age range of 26-35 years, secondary school graduates, and unemployed, respectively. Moreover, $75.9 \%$ and $42.9 \%$ of mothers had a nuclear family, and the income level between 1500 and 3000 Turkish Liras, respectively. Eventually, 81.3\% of the mothers lived in the city center, and $85.7 \%$ did not have a blood relation with their spouses.

\subsection{Knowledge status, information sources of mothers, and their views about newborn screening tests}

Mothers' status of knowledge regarding neonatal screening tests according to mothers' sources of knowledge and their certain opinions about the screening tests is presented in Table 2 . Based on the

\begin{tabular}{|c|c|c|}
\hline Characteristics ( $\mathrm{n}=112)$ & $\mathbf{N}$ & Percentage (\%) \\
\hline \multicolumn{3}{|l|}{ Age } \\
\hline 18 years and younger & 3 & 2.7 \\
\hline $19-25$ & 46 & 41.1 \\
\hline $26-35$ & 48 & 42.9 \\
\hline 36 years and older & 15 & 13.4 \\
\hline \multicolumn{3}{|l|}{ Education } \\
\hline Primary school and below & 16 & 14.3 \\
\hline Secondary School & 34 & 30.4 \\
\hline High school & 31 & 27.7 \\
\hline Undergraduate and higher & 31 & 27.7 \\
\hline \multicolumn{3}{|l|}{ Family Type } \\
\hline Nuclear family & 85 & 75.9 \\
\hline Extended family & 27 & 24.1 \\
\hline \multicolumn{3}{|l|}{ Place of residence } \\
\hline City Center & 91 & 81.3 \\
\hline Town / Village / Township & 21 & 18.8 \\
\hline \multicolumn{3}{|l|}{ Working Status } \\
\hline Employed & 28 & 25.7 \\
\hline Unemployed & 81 & 74.3 \\
\hline \multicolumn{3}{|l|}{ Income Level } \\
\hline Less than $1500 €$ & 37 & 33.0 \\
\hline Between 1500-3000 £ & 48 & 42.9 \\
\hline Over $3000 €$ & 27 & 24.1 \\
\hline \multicolumn{3}{|l|}{ Blood relation } \\
\hline Consanguine marriage & 16 & 14.3 \\
\hline Not applied & 96 & 85.7 \\
\hline \multicolumn{3}{|l|}{ Regular Control } \\
\hline Yes & 105 & 93.8 \\
\hline No & 7 & 6.3 \\
\hline
\end{tabular}

presented data, $73.2 \%$ of mothers were aware of the neonatal screening tests. The evaluation of mothers' sources of knowledge indicated that $81.1 \%, 86.1 \%$, and $83.8 \%$ of mothers were informed about heel stick blood sampling, hearing test, and developmental dysplasia of hip screening from some health personnel, respectively. Moreover, $67.9 \%$ of the mothers stated that the tests shouldn't be performed without parents' consent and 75\% emphasized that

\begin{tabular}{|c|c|c|}
\hline Properties & $\mathbf{N}$ & $\%$ \\
\hline \multicolumn{3}{|c|}{$\begin{array}{l}\text { Status of Knowledge about Newborn Screening Programs } \\
(n=112)\end{array}$} \\
\hline Yes & 82 & 73.2 \\
\hline No & 30 & 26.8 \\
\hline \multicolumn{3}{|c|}{ Information Sources } \\
\hline \multicolumn{3}{|c|}{ Heel blood screening o $($ no $=90)$} \\
\hline Health personnel & 73 & 81.1 \\
\hline Internet & 17 & 18.9 \\
\hline \multicolumn{3}{|c|}{ Hearing screening $(n=79)$} \\
\hline Health personnel & 68 & 86.1 \\
\hline Internet & 11 & 13.9 \\
\hline \multicolumn{3}{|c|}{ Hip dislocation screening $(n=68)$} \\
\hline Health personnel & 57 & 83.8 \\
\hline Internet & 11 & 16.2 \\
\hline \multicolumn{3}{|c|}{ Permission for Newborn screening tests $(n=112)$} \\
\hline Required & 76 & 67.9 \\
\hline Not required & 24 & 21.4 \\
\hline No idea & 12 & 10.7 \\
\hline \multicolumn{3}{|c|}{$\begin{array}{l}\text { If tests are done against payment, will you have the test } \\
\text { done? }(n=112)\end{array}$} \\
\hline Yes & 84 & 75.0 \\
\hline No & 20 & 17.9 \\
\hline No idea & 8 & 7.1 \\
\hline
\end{tabular}




\begin{tabular}{|c|c|c|}
\hline Properties & $\mathbf{N}$ & Percentage (\%) \\
\hline \multicolumn{3}{|c|}{ Knowledge status } \\
\hline \multicolumn{3}{|c|}{ Knowledge about Heel Blood Screening } \\
\hline Yes & 41 & 36.6 \\
\hline No & 71 & 63.4 \\
\hline \multicolumn{3}{|c|}{ Knowledge about Hearing Screening } \\
\hline Yes & 72 & 64.3 \\
\hline No & 40 & 35.7 \\
\hline \multicolumn{3}{|c|}{ Knowledge about Hip Dislocation Screening } \\
\hline Yes & 57 & 50.9 \\
\hline No & 55 & 49.1 \\
\hline \multicolumn{3}{|c|}{ Heel Blood Screening } \\
\hline Beneficial & 103 & 92 \\
\hline Not beneficial & 9 & 8 \\
\hline \multicolumn{3}{|c|}{ Hearing Screening } \\
\hline Beneficial & 103 & 92 \\
\hline Not beneficial & 9 & 8 \\
\hline \multicolumn{3}{|c|}{ Hip Dislocation Screening } \\
\hline Beneficial & 100 & 89.3 \\
\hline Not beneficial & 12 & 10.7 \\
\hline
\end{tabular}

they would get their babies screened even if they need to pay for that.

4.3. Mothers' statuses of knowledge about the objectives of newborn screening tests and their effectiveness

Knowledge statuses of mothers about the objectives of newborn screening tests and their effectiveness are presented in Table 3. Based on the presented data, $63.4 \%$ of the mothers didn't know about the purpose of the heel prick test; however, 3\% and $50.9 \%$ of mothers knew about the hearing test and the purpose of developmental dysplasia of hip screening, respectively. Evaluation of mothers' thoughts on benefits of neonatal screening tests revealed that $92 \%$ of mothers found heel prick and hearing tests useful, and $89.3 \%$ believed in the effectiveness of dysplasia of hip screening.

\subsection{Mothers' status of knowledge about neonatal} screening tests based on their employment status

Based on the data in Table 4, working mothers had more knowledge about the tests, compared to non-working mothers and there was a statistically significant difference between them in this regard $(P=0.028)$. However, no statistically significant difference was observed between the mothers' status of knowledge about the screening tests and other demographic data. Therefore, a single table was created.

\begin{tabular}{lcccc}
\hline $\begin{array}{l}\text { Table 4. Mothers' } \\
\text { screening tests based on their employment status }\end{array}$ & $\begin{array}{c}\text { stat of knowledge about neonatal } \\
\text { Mothers' knowledge of newborn } \\
\text { screening tests }\end{array}$ \\
\hline \multirow{3}{*}{ Working status } & \multicolumn{3}{c}{ No } \\
\cline { 2 - 5 } & \multicolumn{3}{c}{ Yes } & \multicolumn{3}{c}{ Number } & $\%$ \\
\cline { 2 - 5 } & Number & $\%$ & 3 & 10,7 \\
Employed & 25 & 89,3 & 27 & 32,1 \\
Not employed & 57 & 67,9 & & \\
\hline Fisher Test: 4.873 & $\mathrm{P}=0.028$ & &
\end{tabular}

\section{Discussion}

Today, several deadly congenital metabolic diseases can be diagnosed early thanks to the neonatal screening programs that are performed after the birth of the baby. Therefore, an early diagnosis of these diseases can be made in the early neonatal period and newborn infant morbidity and mortality rates have been reduced by appropriate treatment protocols, thanks to these tests $(15,16)$. Accordingly, Neonatal Screening Programs are seen as an essential part of the public health system $(16,17)$.

The improvement of mothers' knowledge about the purpose of these tests reduces their worry and makes them feel better (18). Based on the obtained results, mothers in this study were aware of neonatal screening programs; however, their knowledge was not complete, especially regarding the purpose of the heel prick test. Based on the results of another study, $42 \%$ of the parents believed that the heel prick test is performed only to identify phenylketonuria (19).

In this study, it was found that health personnel were the most significant source of knowledge for mothers to obtain information about neonatal screening programs. Internet, television, and brochures were other sources of access to information; however, they were less favored options, compared to health personnel. The results of another study indicated that $81.8 \%$ of the families get information about tests from the health personnel, which was in line with the results of the present study (19).

Consistent with the results of the present study, the data analysis of Turkey Population and Health Research (TPHR), dated 2013, revealed that mothers get $95 \%$ of their information about prenatal care from their doctors. It is worth mentioning that written materials, such as brochures were not muchpreferred sources of knowledge. This can be attributed to the low education level of participant mothers.

The study findings indicated that most of the mothers would agree to have their infants screened by neonatal tests in the future even if they needed to pay for these tests. Based on the results of another study, $96.7 \%$ of parents defended the idea of free screening tests; however, $68.5 \%$ stated they would welcome these tests whether or not they required payment (19). Another study conducted in Finland indicated that parents were not concerned about test costs (20). The common point in all these studies is that although parents believe that these tests should be free, they will still take the tests even if they are charged for the tests.

More than half of the mothers in the present study asserted that they want their permission (whether or not they want their infants to be screened) to be taken in advance. In a similar study, $82.8 \%$ of the 
participants mentioned this permission requirement (19). However, $46.0 \%$ of mothers in a different study believed that their consent for the performance of the routine screening tests is not required since they believed these tests to be simple and safe (21).

According to the results of the aforementioned studies, it can be concluded that families want to be informed about the content, benefits, and risks involved with the screening tests before deciding to have their newborns screened. On the contrary, research in the USA showed that health personnel believed that getting permission from parents would reduce the number of participants in neonatal screening tests (22).

Moreover, a statistically significant correlation was observed between the employment status of the mothers and their knowledge status about neonatal screening tests. This can be explained by the fact that working mothers' educational level is higher than that of the unemployed mothers, and that they have better access to information.

\section{Conclusion}

The high prevalence of congenital metabolic diseases in Turkey caused by the high rate of consanguineous marriages in this country indicates that today neonatal screening tests are more important than ever. It is essential to increase the parents' knowledge about the subject since having information about these tests increases the chance of their being performed on time and facilitates the early diagnosis and treatment process.

Based on the obtained results, mothers were not sufficiently knowledgeable about screening tests and their objectives; however, they expressed positive views about these tests. Therefore; it is recommended that families should be informed about screening tests through mass media, educational environments, such as pregnant women schools, and screening test centers.

Midwives and nurses are charged with the great responsibility to inform parents at every step of the newborn screening tests. Therefore, it is important to organize in-service training for midwives and nurses to raise their awareness on the subject.

\section{Acknowledgments}

\section{None.}

\section{Footnotes}

Author's contributions: Topuz Ş performed the major part of the study; Taşgit A, Oğuz ŞO designed the study and analyzed the data. Elif Çilesiz E, Gökçe $\mathrm{R}$, and Ülger DA wrote and revised the manuscript. The final version of the manuscript was approved by Topuz Ş.
Conflicts of Interest: The author (s) declared that there is no conflict of interest with respect to the research, authorship, and/or publication of this article.

Ethical Approval: Ethical codes and principles of the Helsinki Declaration have been followed during the study. Written permission and Ethics Committee permission (51/2018) were obtained from the Zekai Tahir Burak Women's Health Training and Research Hospital (New name: Ministry of Health Ankara City Hospital) in the early stages of the study.

Funding/Support: The author(s) received no financial support for the research, authorship, and publication of this study from any public or private organization or institute.

\section{References}

1. Association of Women's Health, Obstetric and Neonatal Nurses. AWHONN position statement. Newborn screening. J Obstet Gynecol Neonatal Nurs. 2016;45(1):135-6. doi: 10.1016/ j.jogn.2015.11.004. [PubMed: 26815807]

2. İçke $\mathrm{S}$, Genç RE. National newborn screening tests carried out with heel lance and their importance. J Pediatr Res. 2017;4(4):186-90. doi: 10.4274/jpr.22932.

3. Infant, child, adolescent follow-up protocols. Ankara: Republic of Turkey Ministry of Health, Public Health Institutions; 2018.

4. Baş N, Turan Z, Uzuner Y. Investigation of the national newborn hearing screening program based on family and health workers' opinions: a case study. J Qualit Res Educ. 2019;7(1):1-27. doi: 10.14689/issn.2148-2624.1.7c1s.6m.

5. Family with Statistics-2016, Report No. 24646. Ankara: Turkey Statistical Institute; 2017.

6. Nar MSS. Medical anthropology: pathological effects of consanguineous marriages. Ankara Univ J. 2012;52:223-40.

7. Uslu HS, Zubarioğlu AU, Bulbul A. Selective metabolic screening from a neonatology perspective. J Acad Res Med Jarem. 2015;5(2):39-46. doi: 10.5152/jarem.2015.755.

8. Akın B, Genç RE. Developmental dysplasia of the hip and the role of midwives in early diagnosis. Br Med J. 2016;5:166-70.

9. Yıldız S, Balcı S, Görak G. The evaluation of taking the Guthrie scan test samples practices and the test results. J Anatolia Nurs Health Sci. 2006;9(1):17-28.

10. Küçükyılmaz E, Tahta T. The role of the midwife in the diagnosis of congenital metabolic diseases. 6th International 10th National Midwifery Students Congress, Sivas, Turkey; 2019. P. 80-1.

11. Doğruel H, Atalar H, Yavuz OY, Uraş İ, Günay C, Saylı UC. To evaluate the incidence of developmental dysplasia of the hip and screening programs in Turkey. J Med Sci. 2008;28(3): 357-60.

12. Tural Buyuk E. Mothers' knowledge of heel stick blood screening operation applied to their babies. Gümüşhane Univ J Health Sci. 2014;3(3):883.

13. Evcili F, Demirel G, Yurtsal ZB, Yılmaz EA. The effect on mothers' knowledge level training of newborn screening test. Gümüşhane Univ J Health Sci. 2017;6(1):80-6.

14. Evcili F, Cesur B, Yurtsal B, Kaya N. Views of mothers about newborn screening tests and participation status in screening programs. Mersin Univ J Health Sci. 2017;10:25-35.

15. Guthrie R. The origin of newborn screening. Screening. 1992;1:5-15. doi: 10.1016/0925-6164(92)90025-z. [PubMed: 11615143].

16. Wilcken B, Wiley V. Newborn screening. Pathology. 2008; 40(2):104-15. doi: 10.1080/00313020701813743. [PubMed: 18203033].

17. Therrell BL, Padilla CD, Loeber JG, Kneisser I, Saadallah A, Borrajo GJ, et al. Current status of newborn screening worldwide: 2015. Semin Perinatol. 2015;39(3):171-87. doi: 
10.1053/j.semperi.2015.03.002. [PubMed: 25979780].

18. Little CM, Lewis JA. Newborn screening. Newborn Infant Nurs Rev. 2008;8(1):3-9. doi: 10.1053/j.nainr.2007.12.004.

19. Arslan A. Children aged 0-1 with parents about the idea of expanded newborn screening program. [Master Thesis]. Istanbul, Turkey Marmara University; 2010.

20. Huang MC, Lee CK, Lin SJ, Lu IC. Parental consent for newborn screening in southern Taiwan. J Med Ethics. 2005;31(11):6214. doi: 10.1136/jme.2004.010074. [PubMed: 16269553].
21. Faden R, Chwalow AJ, Holtzman NA, Horn SD. A survey to evaluate parental consent as public policy for newborn screening. Am J Public Health. 1982;72(12):1347-51. doi: 10.2105/ajph.72.12.1347. [PubMed: 7137431].

22. Cusworth-Aerts J. Oral and written information about newborn screening should be concise and given to parents by primary prenatal care providers. Evid Based Nurs. 2007;10(1):27. doi: 10.1136/ebn.10.1.27. [PubMed: 17218301]. 